\title{
Doctor-patient relationships in primary care Doctor, help! My child has cancer
}

The following pair of articles started with a personal view from the mother of a child who had died of neuroblastoma. In it she argued that her general practitioner, although generally supportive, should have taken more of the initiative in offering help during her child's illness. We invited her general practitioner to respond.

\section{The parent}

BMJ 1999;319:554-6 $\quad$ A call for help may be an obvious one, from parents trying to come to terms with their child having cancer, or a hidden plea from parents outwardly coping with the demands thrust on them but who are inwardly desperately struggling. Are both these calls for help recognised and responded to by the family doctor?

My family's personal experience over the past 18 months has led me to ask many questions about the role of a general practitioner when a child patient develops cancer. In seeking answers, I have had discussions with several general practitioners, hospital doctors, and support staff and with other families affected by neuroblastoma or other life threatening childhood diseases. Each situation is unique, each family has individual needs, and each general practitioner has his or her own approach. However, there seem to be certain general patterns and problems. Before discussing these, I present our case history, which illustrates why I feel so strongly about the issue and believe that there is much to be learnt and changed.

\section{Case history}

At the start of 1996 we were a happy, healthy family with much to enjoy and look forward to. My husband and I were in our late $30 \mathrm{~s}$ and had three boys, aged 11, 8 , and 2. Our general practitioner, with whom we had registered during my pregnancy with our first son, had been present at the home births of our second and third boys. We had a good relationship with our doctor, although none of the family had needed to see him often, and never for any serious medical problem.

In July 1996 we were starting to worry about Antony, our youngest son, who was not eating, seemed very tired and listless, and was generally unhappy. By the end of August our general practitioner had referred him to the local hospital for further tests. The ultrasound scan showed a large abdominal mass. Antony was transferred to Great Ormond Street Hospital, and within a few days stage 4 neuroblastoma was diagnosed. He was a very sick little boy, requiring total parenteral nutrition through a Hickman line, and he underwent an intensive course of chemotherapy over five months. He initially responded well to treatment and was able to spend more time at home than in Great Ormond Street or the local hospital. Throughout his illness he needed feeding through a nasogastric tube and had to cope with all kinds of frightening medical interventions, from bone scans to blood transfusions, in addition to being seen and touched by one unfamiliar person after another, a frightening ordeal in itself for a child of his age.
In February 1997 a major surgical operation to remove the tumour proved unsuccessful as the neuroblastoma cells were too active. After that, there was no treatment protocol to follow and the outlook was grim. In April he underwent systemic radiation treatment, with metaiodobenzylguanidine labelled with radioiodine, at the Middlesex Hospital in another attempt to control the cancer cells. He gained two weeks of good quality life but developed a lung infection when the neuroblastoma cells once again became aggressive. Antony died at home aged 40 months.

In the space of less than a year, our lives had been thrown into total disarray. Our family doctor, contrary to my expectations, did not maintain contact with us during our son's illness until the final stages. We were surprised and hurt by his attitude and mistakenly took his lack of contact as a lack of interest. Later, he said that he had not wanted to intrude, to be yet another superfluous medical person for us to deal with. Knowing that we were "sensible, articulate" parents, he had expected us to take the initiative to contact him. Sensible and articulate we may be under normal circumstances, but this was an exceptional situation. Regular contact with us should have been an integral part of his role as our family doctor.

\section{Lessons to be learnt}

Our family circumstances and needs were specific to us, but whenever there is a very sick child the same underlying criterion applies: the family is on an emotional roller coaster, feelings and tension are high, and the parents are no longer in control and are being tested to the limit. The family requires moral and practical help and encouragement to cope with the medical treatment that their child is receiving, which is often unpleasant, invasive, and distressing for the child and parents alike.

It is inappropriate and unnecessary for a family doctor to have in-depth knowledge of the many and varied forms of childhood cancer. What is vital is that the general practitioner is able to act appropriately, referring a child for specialist treatment when it becomes apparent that this is not a common childhood ailment. Once the child is at a specialist treatment centre, what then? Between treatments, there will be regular home visits from a community paediatric nurse or a Macmillan nurse. The child may also have frequent visits to the local hospital for blood transfusions or for treatment of complications. Does the family general practitioner need to call too? Yes, I believe he or she has a vital role to play. 


\section{The constant factor}

In an unfamiliar and often frightening medical world, the family general practitioner is the one constant factor. He or she knows the family, as a whole, better than any other doctor or nurse. The family doctor was there before and as the child fell ill and will be the one left to pick up the pieces once treatment has finished, whether the child is in remission or has died. The doctor's continued contact with the family, in whatever capacity is mutually felt appropriate, can only help and can be a source of reassurance to the parents.

\section{Supportive role}

The clinical care of the child is out of the general practitioner's hands, and it is reasonable for the doctor to expect the parents to make contact if they have medical problems of their own. If there is no clinical need, however, the initiative needs to come from the general practitioner, not just once, but at regular intervals throughout the illness. Even parents who are normally articulate, sensible, coping people have quite different needs and behaviour patterns in such extreme circumstances. They are unlikely to initiate contact with their general practitioner just for a chat, yet this may be exactly what is needed.

\section{Communication}

Poor communication is the root of many problems, whether it is between individuals, departments, or organisations. Communication between all the various bodies concerned is vital in this situation.

Communication between treatment centre and general practitioner-The general practitioner needs to be informed about the child's disease-the confirmed diagnosis, the prognosis, the treatment the child will be receiving-and to be informed each time the child is expected home from hospital or when there is a major development, good or bad. The general practitioner should be encouraged by the treatment centre to contact the parents at an early stage in order to maintain a connection throughout the child's illness at whatever level is appropriate in each case. The general practitioner should also be encouraged to telephone the treatment centre should he or she have any queries about the disease or the child's current condition.

\section{The doctor}

In responding to the request to give my view, I find myself faced with a flood of contradictory thoughts and emotions. I do not want anything I write to be seen as defensive self justification, the implication being that there is something to apologise for, yet the very act of writing can be viewed as an expiation of some complex feelings. At the base of these is the unique and multi-layered relationship between general practitioner and patient, whether an individual or a family.

Around the professional aspects of doctors' duties and responsibilities and patients' rights and expectations (and their own responsibilities) are interwoven the personal human qualities of acquaintance, amicability, fondness, and shared experiences. It is this remarkable fusion over time that gives general
Communication between local hospital and general practitioner-The general practitioner should be kept informed of the care the child is receiving locally. The general practitioner should be considered part of the team caring for the sick child, and not excluded because direct medical intervention is not required from him or her.

Communication between general practitioner and familyOnce the child has been transferred to a treatment centre, the parents may turn to their general practitioner for reassurance or guidance. Usually, however, they are swept up in the turmoil of their child's care at the treatment centre and do not consider contacting the general practitioner unless they have a specific clinical need. The initiative to re-establish contact must therefore come from the general practitioner, whether by telephone, by letter, or in person. Early contact is important to reinforce the background support that the general practitioner can provide during the child's illness. Some parents may not feel that contact with the general practitioner is of use, but at least the offer has been made, and the parents will be more likely to turn to the general practitioner if their circumstances and needs change during the illness. Mutual early agreement could be reached on how regularly the general practitioner should make contact to maintain appropriate involvement. If contact has been maintained throughout the illness, doctor and parents may find it easier to cope with the child's death and its aftermath.

\section{The challenge to general practitioners}

Cancer may no longer be the taboo subject it once was. Looking after adult and elderly patients who are suffering from cancer is a challenging but fairly familiar part of a general practitioner's work, as is caring for dying patients. However, caring for a child with cancer or a dying child is far more emotionally charged for all concerned, far more challenging, and far from routine. It is a challenge that general practitioners must confront rather than shy away from once the medical care of the child is in the hands of the specialists. How prepared are general practitioners to take this challenge on board? practice its strength and rewards. However, unlike any other relationship, the circumstances dictate a very one sided exposure. I was privileged to be closely involved with the births of Antony and his brothers. Being allowed access to this most intimate of family events continues to give me great personal and professional satisfaction, but my patients do not have the same access to my life, creating difficulties in their interpreting or even being aware of my own emotional responses to my professional duties. The boundaries created by the relationship, though not rigid, are, I think, necessary for general practice to be sustainable over the years, but each practitioner defines them for himself or herself.

This definition is mainly driven by an individual's emotional milieu. The need of the doctor to give aid to 
a patient-whether in the form of clinical skills, access to facilities, or emotional support-in both good and bad times is a human not a professionally acquired one. But every situation is unique. In today's medical environment, with its proliferation of guidelines and protocols and the emphasis on efficiency, there is little to help the family doctor in this situation apart from personal experience and inclination.

Dealing with such an awful condition as Antony's, raises all sorts of questions. I have two children of my own and can only imagine what Antony's illness and death have meant to his family. At a discussion early in his illness I was asked what I felt my role was to be, given the input and expertise of Great Ormond Street Hospital, which took over Antony's care. I replied that I was still the family doctor and remained a port, if not the first port, of call. Unfortunately, as is its wont, Great Ormond Street Hospital took over completely, and only in the final stages was any communication from the hospital forthcoming. (In this respect matters are improving, but we are still a long way from a satisfactory team approach to serious and terminal childhood illnesses.) I also had and still have an anxiety over the degree to which anyone, professional or not,

\section{Appendix}

Neuroblastoma is diagnosed in about 100 children in the United Kingdom each year. Most of these are less than 4 years old. Neuroblastoma may arise at any site where sympathetic neural tissue is found, but the most common site is the abdomen. The tumour may present with a variety of symptoms, although most children initially present with rather vague symptoms that may be mistaken for a viral illness. Some children present with abdominal pain or a limp because of bony involvement.

Treatment of neuroblastoma depends on the site of the tumour, the stage or spread of the disease, and the age of the child. Most children with localised tumours (stages 1 and 2) can be cured, and infants under 1 year old tend to have a better outlook. However, in $65 \%$ of can or should intrude into the family space in situations such as this. The obvious answer might seem to be a process of communication, but that seems to have failed, at least initially. By chance, I was visiting at the moment of Antony's death, and the sense of gross invasion at such a private time still haunts me.

The suggestion that I had misinterpreted the family's needs-which, perhaps, were never signalled-and that I did not do something which might have made a difference and which on other occasions I have done has led me to re-examine the special needs of a group of patients who, as Antony's mother states, will only ever be a very small portion of a general practitioner's work. The complexity and uniqueness of every doctorpatient relationship is a concept that, as a general practitioner trainer and course organiser, I try to emphasise to all general practitioner registrars, but one that has been crucially underlined by my personal experience. That Antony's parents have been able to be open and frank with me about their feelings, and continue to consult me as their general practitioner as they face the future, reinforces what has to be a dynamic relationship, growing and developing with the vicissitudes of shared experience.

cases the disease is widespread and highly aggressive (stage 4), and the prognosis for these children is poor.

The Neuroblastoma Society has three primary roles:

- To find a cure for neuroblastoma through funding clinical and scientific research

- To raise awareness of neuroblastoma with the public and with the medical profession

- To give spiritual and practical support to those with neuroblastoma, and their families.

An information booklet about neuroblastoma is available from the society. For further details, contact Dr Barry Pizer, Alder Hey Children's Hospital, Eaton Road, Liverpool L12 2AP (tel: 01512525294 fax: $01512525676)$.

\section{A memorable patient The accordionist}

"Cedric" was a house call in Kibblesworth. I knew him slightly from a couple of previous visits to his equally ancient wife, now sadly passed on. I didn't want to go to Kibblesworth. It's a small village stranded on the other side of the practice, and in the opposite direction to a cosy cup of lunchtime tea at home. Cedric's little bungalow was clearly missing the attention it used to have from his wife. He had had some sort of episode on the way to the post office where "he wasn't himself," not sure of where he was, etc, but he seemed to have more or less recovered.

While musing on the diagnostic possibilities I saw a music stand and a small bass guitar amp in the corner. My curiosity was aroused; it was hard to visualise 86 year old Cedric as a rocker (other than in a parkinsonian way), so I asked about his music. His eyes lit up, and from under a cloth he produced a magnificent black and silver accordion. He invited me to play it, which I did, badly. Despite his arthritic fingers he played it himself, a tune that he had written, a lovely lyrical tune. Then he showed me a trunk full of accordion music
"That's worth a pretty penny," he said proudly, pointing to dog eared music costing three and sixpence a sheet.Then he turned to his photographs of his army band playing days after the war. His eyes misted up and he wasn't really with me. But I wasn't in the bungalow either. I, too, was in smoky postwar dance halls listening to the band.

"We were the best band around," he said. He should have turned professional, but he went down the pit instead. Perhaps that was what had made him so hardy. He continued to reminisce.

"Ah, but once they just started vamping on the bass, the accordion's days were numbered," he finished up sadly, as he carefully replaced the cloth. There was nothing more to say. I left for a late lunch.

And the diagnosis? I never did make one, but at least now I had visited a person, not a patient, and it made my day.

Paul Vincent, general practitioner, Birtley, County Durham 